\title{
Diseño de un plan estratégico de marketing educativo apoyado en el uso de las tecnologías de información y comunicación en el Instituto tecnológico superior de Puerto Peñasco
}

\author{
Maria E. Garcia-Bribiesca ${ }^{a}$, Diana E. Lopez-Chacon ${ }^{b}$, Daniel A. Osuna-Talamantes ${ }^{c}$, \\ Javier Ortiz-Vidaca ${ }^{d}$ \\ a María Elena García Bribiesca M.Ed. es profesor de tiemplo completo asociado "A" de Licenciatura \\ en administración en el Instituto tecnológico superior de Puerto Peñasco, Sonora, México. garcia- \\ mariaelena@itspp.edu.mx (autor corresponsal) \\ ${ }^{\mathrm{b}}$ M.Ed. Diana Elizabeth López Chacón es profesora de tiempo completo titular "A" de la Ingeniería \\ en sistemas computacionales en el Instituto tecnológico superior de Puerto Peñasco, Sonora, \\ México.1opez-diana@itspp.edu.mx \\ " MTIC. Daniel Alonso Osuna Talamantes es profesor de tiemplo completo asociado "A" de \\ Ingeniería en sistemas computacionales en el Instituto tecnológico superior de Puerto Peñasco, \\ Sonora, México daosuna@live.com.mx \\ d M.Ed. Javier Ortíz Vidaca es profesor de tiempo completo titular "A" Ingeniería civil en el Instituto \\ tecnológico superior de Puerto Peñasco, Sonora, México. ortíz-javier@itspp.edu.mx
}

\begin{abstract}
Resumen
Este artículo presenta los resultados de una investigación que surge durante el año 2015, propuesta del cuerpo académico en formación "Gestión educativa e innovación tecnológica" del Instituto tecnológico superior de Puerto Peñasco, la idea es identificar las áreas de oportunidad y diseñar las estrategias para incrementar la promoción de los programas educativos que oferta la institución, planteando la posibilidad de su implementación en la que se involucren docentes, estudiantes y egresados. Desarrollando propuestas y ofreciendo soluciones para lograr incrementar la matrícula del Instituto tecnológico superior de Puerto Peñasco, estableciendo un vínculo con el target o público objetivo. Como conclusión se identificará la ventaja competitiva que puede llegar a tener el Instituto tecnológico superior de Puerto Peñasco con la finalidad de mantener su posicionamiento a nivel regional como la primera opción de estudios a nivel superior de calidad educativa obteniendo como resultado el incremento de estudiantes en las cuatro carreras generando profesionistas que sean competitivos y éticos.
\end{abstract}

Palabras clave: Promoción, educativa, competitividad, posicionamiento y calidad. 
Diseño de un Plan Estratégico de Marketing Educativo apoyado en el uso de las tic's en el Instituto Tecnológico Superior de Puerto Peñasco

\section{Introducción}

Entender el marketing educativo como un proceso de investigación de necesidades sociales para desarrollar servicios educativos tendientes a satisfacerlas es tarea de toda institución educativa, para ello se requiere como premisa previa un estudio que dé cuenta de la importancia de la aplicación de este plan estratégico mercadológico como parte fundamental en la vida de toda entidad educativa. Se propone por tanto, introducir este estudio con una serie de elementos conceptuales y vivenciales de diferentes centros educativos a fin de poder comprender y situarnos con mayor claridad en el contexto y actuación del instituto. A lo largo de esta investigación se irá concretando cuáles pueden ser esas actuaciones para nuestra institución educativa basándose en un análisis que identifique las fortalezas, oportunidades, debilidades y amenazas entre otras herramientas. Finalmente se dedicará una parte de la investigación a desarrollar un planteamiento prospectivo que nos permitirá revisar el futuro de nuestro tecnológico con el apoyo de las tecnologías de comunicación. Ver Tabla 1.

Tabla 1. Análisis de las fortalezas, debilidades, amenazas y oportunidaddes del Institutot tecnológico superior de Puerto Peñasco.

\begin{tabular}{|c|c|c|c|}
\hline \multicolumn{4}{|c|}{ Análisis FODA } \\
\hline Fortalezas & Debilidades & Amenazas & Oportunidades \\
\hline $\begin{array}{l}\text { Cuenta con dos carreras } \\
\text { acreditadas la } \\
\text { Licenciatura en } \\
\text { administración por el } \\
\text { Consejo de acreditación } \\
\text { en ciencias } \\
\text { administrativas, } \\
\text { contables y afines y la } \\
\text { Ingeniería en sistemas } \\
\text { computacionales por el } \\
\text { Consejo de acreditación } \\
\text { de la enseñanza de la } \\
\text { ingeniería. }\end{array}$ & $\begin{array}{l}\text { Falta de difusión de las } \\
\text { actividades y eventos } \\
\text { tanto internos como } \\
\text { externos de la escuela. }\end{array}$ & $\begin{array}{l}\text { Existe una Institución de } \\
\text { nivel superior que oferta } \\
\text { carreras similares a más } \\
\text { bajo costo y en menor } \\
\text { tiempo. }\end{array}$ & $\begin{array}{l}\text { Cuenta con prestigio y } \\
\text { antigüedad en la } \\
\text { comunidad y la región. }\end{array}$ \\
\hline $\begin{array}{l}\text { Cuenta con certificación } \\
\text { ISO 9001-2008. }\end{array}$ & Falta de promoción. & $\begin{array}{l}\mathrm{Si} \text { la matrícula sigue } \\
\text { decayendo puede tender a } \\
\text { cerrar carreras o } \\
\text { desaparecer la escuela. }\end{array}$ & $\begin{array}{l}\text { Se pretende iniciar con la } \\
\text { impartición de diplomados } \\
\text { dirigidos hacia la } \\
\text { comunidad en general } \\
\text { específicamente en el área } \\
\text { de administración. } \\
\end{array}$ \\
\hline $\begin{array}{l}\text { Es la única Institución de } \\
\text { nivel superior que ofrece } \\
\text { la carrera de Ingeniería } \\
\text { civil en la comunidad y } \\
\text { la región. }\end{array}$ & $\begin{array}{l}\text { No se cuenta con } \\
\text { instalaciones deportivas } \\
\text { propias. }\end{array}$ & $\begin{array}{l}\text { Cuenta con solo cuatro } \\
\text { carreras Licenciatura en } \\
\text { administración, Ingeniería } \\
\text { industrial, Ingeniería civil, } \\
\text { Ingeniería en sistemas } \\
\text { computacionales. }\end{array}$ & $\begin{array}{l}\text { Realiza congresos propios } \\
\text { a nivel nacional e } \\
\text { internacional. }\end{array}$ \\
\hline
\end{tabular}




\section{Planteamiento del problema}

Las instituciones educativas de nivel superior son parte importante para la formación de profesionistas capaces de transformar y promover el conocimiento en beneficio de la sociedad, como es el caso del Instituto tecnológico superior de Puerto Peñasco, en Sonora.

El Instituto tecnológico superior de Puerto Peñasco es una institución educativa cuya misión es "Formar profesionistas con perfiles que contengan un alto sentido crítico, ético, de valores y creatividad para integrarse al impulso local, regional y nacional, brindando para ello formación académica integral, razón por la cual es importante contar con programas educativos actualizados que brinden el mejor nivel de calidad para gozar el reconocimiento de la sociedad.

Actualmente este centro educativo tiene serios problemas reflejados en la reducción de su matrícula y en deserción de alumnos para irse a continuar sus estudios a otra institución esto de acuerdo a la información estadística adquirida en el departamento de servicios escolares en relación a la matrícula, permite constatar la baja demanda del servicio educativo que cada año se registra en la institución, de igual manera, la excedencia de personal docente y administrativo, así como un posible cierre de la misma en el futuro, todo ello provocado principalmente por factores como la baja calidad educativa que brindan algunos docentes que no tienen una capacitación y formación adecuada para la asignatura que se imparte formando así pocos profesionistas preparados para hacer frente a los retos que exige una sociedad en constante cambio. Otro factor importante es la deficiencia de algunos departamentos administrativos en el conocimiento de sus funciones logrando con ello conflictos entre alumno-institución, de igual manera la mínima identidad institucional entre todos los sujetos que la conforman reflejándose en el comportamiento que tiene el alumno hacia su centro educativo así como los conflictos individuales y grupales que existen entre docentes-administrativos que repercute de manera sustancial en la forma de cómo la sociedad cataloga a la institución. Parte importante es la carencia de infraestructura relacionada principalmente a la deportiva que hace que los futuros alumnos no duden en elegir otra universidad por sus atributos tecnológicos y deportivos, sin mencionar factores externos a la institución como lo son formación del alumno en casa, escuela media superior, la economía, entre otros.

De acuerdo a todo lo anterior surge la siguiente pregunta de investigación ¿Qué estrategias deberán realizarse para incrementar la demanda del servicio educativo en el Instituto tecnológico superior de Puerto Peñasco, en Sonora? 


\section{Objetivo general}

Diseñar un plan de estrategias de mercadotecnia educacional para incrementar la demanda del servicio educativo en el "Instituto tecnológico superior de Puerto Peñasco a través del uso y aplicación de las tecnologías de la información y comunicación".

\section{Hipótesis}

Se identificarán las causas relacionadas directamente con el decrecimiento de la matrícula en el tecnologico durante los últimos tres años detectando las áreas de oportunidad tanto internas como externas.

El plan estratégico de mercadotecnia educacional contribuirá al incremento de la demanda del servicio educativo del Instituto tecnológico superior de Puerto Peñasco.

\section{Justificación}

El Instituto tecnológico superior de Puerto Peñasco nace un día 04 de septiembre en el año 2000 con una matrícula de 165 alumnos lo cual vino a darle una opción real de estudios a los jóvenes de Puerto Peñasco y municipios aledaños. Al inicio este centro educativo contó con dos programas educativos: Licenciatura en administración, opción empresas turísticas e ingeniería industrial, opción desarrollo empresarial. A través del tiempo la institución ve la necesidad de ofertar la carrera de Ingeniería en sistemas computacionales la cual, contrajo el aumento gradual en el registro de alumnos, docentes y personal administrativo. Finalmente en el año 2009 se tiene el primer registro de alumnos en la carrera de ingeniería civil fortaleciendo así la oferta académica del instituto. En la actualidad según las estadísticas proporcionadas por el departamento de servicios escolares la matrícula de los alumnos del Instituto tecnológico superior de Puerto Peñasco ha ido a la baja de acuerdo a factores internos y externos a la institución educativa, lo cual, se ve afectado en la reducción de grupos, racionalización de personal docente y administrativo como consecuencia de la poca población estudiantil que inclusive siendo extremista, de seguir en esta tendencia logrará el cierre de la institución educativa. 
La situación que se debe encarar hoy en día es preocupante; pues la fuerte e intensa competencia de otras instituciones educativas que aplican la mercadotecnia educacional pone a la institución en desventaja acentuándose el decrecimiento del servicio educativo.

En virtud de lo anterior, se justifica plenamente el interés y la urgencia de realizar la investigación del plan estratégico mercadológico educacional para conocer y satisfacer las expectativas, necesidades e interés que requiere el mercado (alumnos) actual, logrando con ello incrementar y satisfacer la demanda del servicio educativo en la institución.

\section{Metodología}

En este estudio se parte de la premisa del plan estratégico de mercadotecnia educacional mismo que será abordado a través de diferentes teóricos. Se pretende realizar un estudio descriptivo buscando determinar causas y efectos del problema de investigación y dada la naturaleza del trabajo se utilizará una metodología cualitativa inductiva apoyada por las técnicas de encuesta a través de la recolección de datos con la finalidad de obtener información de primera mano de los sujetos de estudio. Los aspectos a investigar se relacionan con los contenidos y objetivos de un plan estratégico de mercadotecnia educacional y el impacto del programa de estratégico de mercadotecnia educacional en el instituto.

\section{Resumen de resultados}

Al finalizar el presente estudio y una vez analizados los resultados obtenidos a través de la investigación se puede concluir que es un buen proyecto para lograr beneficios como el fortalecimiento del Instituto tecnológico a través de un plan estratégico de promoción educativa lo cual repercutirá en el posicionamiento como una institución de calidad obteniendo una clara ventaja competitiva a nivel regional.

A través de ésta investigación se comprobó que si se aplica una efectiva promoción y difusión y una vez subsanadas las áreas de oportunidad el Instituto tecnológico superior de Puerto Peñasco lograría posicionarse como la mejor opción para estudiar el nivel superior en la región de Puerto Peñasco, Sonora. 


\section{Recomendaciones}

Los interesados en continuar esta investigación podrían concentrarse en realizar el seguimiento bajo la implementación de las diversas estrategias propuestas al finalizar el presente estudio lo cual atraería la atención de los estudiantes de nivel medio superior para cursar algunas de las carreras que se ofertan logrando la consolidación a local y regional del Instituto tecnológico superior de Puerto Peñasco, Sonora.

Por otra parte el considerar el diseño de un plan anual de mercadotecnia y un sistema de información de mercadotecnia es muy importante, en el plan se establecen metas de alumnos por año, se define el mercado al cual enfocarse, se establece el posicionamiento que se busca tanto a nivel local como regional, se analiza también la competencia, se definen estrategias de promoción, descuentos y los proyectos prioritarios de promoción. Dentro del mismo plan se genera la imagen a proyectar, las estrategias de publicidad, medios, costos y calendarización aunado a esto, se tiene que iniciar con la generación de una base de datos, crear un sistema de ventas y conocer las razones por las cuales se inscriben los alumnos y cómo se enteran de la institución. El tener un buen plan de marketing se refleja en la mejora del presupuesto. La ventaja del sistema de información de mercadotecnia en este caso es que los siguientes años se gastará menos en investigación.

Se puede realizar la práctica del mercado directo y seguimiento de prospectos, las cifras señalan que el $60 \%$ se inscribe por recomendación, al diseñar el mercado directo se llega de manera personal de uno a uno no masivo, con ello se va generando una base de datos para facilitar la decisión y atender las demandas.

Entre las estrategias enfocadas al uso y aprovechamiento de las tecnologías de información se recomienda generar un sistema de información de mercadotecnia que contenga toda la información relativa a la difusión de las diferentes actividades institucionales dentro y fuera de la región la idea es producir informes periódicos que se encuentren disponibles cuando se requiera, mantener actualizada esta información para identificar las tendencias y poder predecir lo que sucederá en el entorno. Para ello se pueden considerar los siguientes índices mercadológicos: población de la ciudad, población de las escuelas visitadas. Identificar a cuantas personas se impactó con el mensaje, cuantas se mostraron interesadas, a quienes se les dio seguimiento, qué cantidad de alumnos se inscribieron en esta escuela y cuántos en otras escuelas, ubicar además qué cantidad de estudiantes se inscribieron en cada carrera.

Se recomienda también el uso del marketing online que es la forma de más rápido crecimiento del marketing directo en la práctica el marketing está cambiando para aprovechar las tecnologías de internet de hoy. Las tendencias modernas son a través del social media como son: facebook, you tube, twitter, creación de blogs por carrera entre 
otras. Cabe resaltar que es de suma importancia habilitar dentro de la institución el puesto de un community manager quien será responsable de mantener contacto directo con el target o público objetivo y actualizar de manera constante la información, la publicidad online se ha convertido en un medio muy importante. Por último la publicidad viral es la versión en internet del marketing de boca en boca, el marketing viral implica la creación de un sitio web, video, correo electrónico, mensaje móvil, publicidad u otro evento de marketing que sea tan contagioso que los clientes lo busquen o compartan a sus amigos. Otra estrategia sería el envío de correo electrónico directo a las cuentas del público objetivo pues cuando se usa de manera correcta el correo electrónico puede ser el medio por excelencia del marketing directo éste medio permite enviar mensajes personalizados capaces de cultivar la relación entre las herramientas que se pueden enviar se podría contar con información general sobre la escuela. El único inconveniente de ésta estrategia es el famoso spam que puede generar correos no deseados o llamados también "basura". En un futuro se recomienda de la misma manera incluir el marketing móvil dirigido a los públicos en movimiento mediante teléfonos móviles, aplicaciones para teléfonos inteligentes, tablets y otros aparatos de comunicación no fijos además de nuevas estrategias implementadas a través de las tecnologías de la información y comunicación.

\section{Referencias bibliográficas}

ACERENZA, M. (2005). Promoción turística: un enfoque metodológico (7th ed.). México: Trillas.

AMBROSIO, V. (2000). Plan de marketing paso a paso (3rd ed.). Amsterdam: Prentice Hall.

FISHER, L., \& Espejo, J. (2011). Mercadotecnia. México: McGraw-Hill.

KOTLER, P. (2008). Dirección de marketing. México D.F. (México): Pearson Educación.

RAMÍREZ Cavassa, C. (2007). Marketing turístico. Alcalá de Guadaira: MAD.

SALLENAVE, Jean-Paul. (1993). Gerencia y planeación estratégica. Bogotá: Grupo Editorial Norma.

HERNÁNDEZ Sampieri, R., Fernández Collado, C., Baptista Lucio, P., Méndez Valencia, S., \& Mendoza Torres, C. (2003). Metodología de la investigación. México, D.F.: McGraw-Hill Education.

\section{Fuentes Web}

MATÍAS Roca, Marta (2010) El Marketing digital en las Empresas. España. Recuperado de https://docplayer.es/1467807-Marketing-digital-en-la-empresa-marta-matias-roca-lasredes-sociales-sobre-la-autora.html. 
Diseño de un Plan Estratégico de Marketing Educativo apoyado en el uso de las tic's en el Instituto Tecnológico Superior de Puerto Peñasco

PORTAL EDUCATIVO (2018). Portal educativo - Conectando neuronas. Portaleducativo.net. Recuperado el 4 de Julio del 2018, a partir de https://www.portaleducativo.net. 